\title{
Model Examination for the Effect of Treading Stress on Young Green Barley (Hordeum vulgare)
}

\author{
Ryota Koga $^{1,2}$, Tianxiao Meng ${ }^{1}$, Eriko Nakamura ${ }^{1}$, Chizuru Miura ${ }^{1}$, Nobuto Irino ${ }^{1,2}$, Shoji Yahara ${ }^{3}$, \\ Ryuichiro Kondo $^{{ }^{*}}$ \\ ${ }^{1}$ Department of Agro-Environmental Science, Faculty of Agriculture, Kyushu University, Fukuoka, Japan; ${ }^{2}$ Asahi Ryokuken Co., \\ Ltd., Fukuoka, Japan; ${ }^{3}$ Graduate School of Pharmaceutical Sciences, Kumamoto University, Kumamoto, Japan. \\ Email: "ryukondo@agr.kyushu-u.ac.jp
}

Received October $4^{\text {th }}, 2012$; revised November $17^{\text {th }}, 2012$; accepted December $20^{\text {th }}, 2012$

\begin{abstract}
Treading barley ("Mugifumi" in Japanese) is a barley culturing process that is unique and indispensable in Japan. Generally, roller machines or human feet are used to tread young barley several times (Figure 1). As a model examination, a stainless steel instrument was used for treading barley in this study (Figure 2(a)). Treading damages plants and decreases growth, such as the height and weight of aerial parts, which then recover gradually. In our study, the total amino acid contents increased with the treading stress. The treading stress induced a 1.7-fold increase in aspartic acid contents and an approximately 1.6-fold increase in glutamic acid, proline, cystine, and methionine contents. Isolation and purification suggested that the main components of the methanol-eluted fraction from the young green barley were six known phenolic compounds. Saponarin and lutonarin were the main components. The saponarin content was about $160 \mathrm{mg} / \mathrm{g}$ (methanol-soluble fraction) at 10 days after germination. We found that the higher antioxidant activity was due to the increased lutonarin/saponarin ratio from $10 \%$ to $24 \%$. Therefore, our results suggest that treading stress is useful for young green barley.
\end{abstract}

Keywords: Hordeum vulgare; Treading Stress; Mugifumi; Flavonoid; Amino Acid; Antioxidant Activity

\section{Introduction}

Barley (Hordeum vulgare L.) is a plant widely distributed and cultivated as cereal grain. Since it was one of the earliest cultivated cereal grains, there have been many reports about the effect of external stresses on barley growth, such as the soil mineral content, short-term, drought, light, and harm from insects. In mineral deficiency or mineral overload and culture media, the following has been reported regarding iron, manganese, and cadmium.

Iron is very important for chlorophyll synthesis, and plants subjected to iron deficiency exhibited severe chlorosis, accompanied by a significant biomass reduction [1]. Iron chlorosis is very common in alkaline soils such as calcareous ones, since iron availability is limited by high $\mathrm{pH}$. Plants growing in alkaline soils would thus be subjected simultaneously to salinity and iron deficiency. Whereas, for the barley in iron-limiting media, phytosiderophore release from the roots into the rhizosphere is stimulated to dissolve soluble iron compounds and enhance iron uptake in the form of iron-mugineic acid complex [2].

${ }^{*}$ Corresponding author.
Manganese toxicity ( $2.5 \mu \mathrm{M}$ manganese) is expressed as reduced dry matter yield, redistribution of growth, mild interveinal chlorosis on younger leaves, brown spots on older leaves and stems, phytosiderophore release from roots, gradual desiccation of older leaves, and root browning. Application of additional iron $(100 \mu \mathrm{M})$ to manganese-stressed plants fully counteracted manganese-induced iron deficiency symptoms, recovered total dry matter yield partially, and changed the plant's composition and accumulation of essential mineral nutrients [3].

Cadmium is a widely spread environmental pollutant. It has no biological function, but is easily assimilated by plants and is toxic at even low concentrations. Cadmiuminduced membrane damages as well as changes in protein and free amino acids contents of barley plants have been reported. The content of malondialdehyde equivalents in both roots and leaves increased 2- to 3-fold, indicating oxidative damage. Cadmium treatment enhanced membrane lipid peroxidation and potassium ionleakage from plant tissue, as well as decreasing the chlorophyll content in barley plants. Cadmium also diminished the contents of both soluble protein and glutamic 

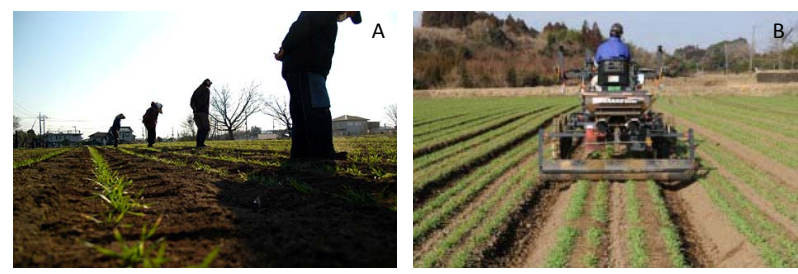

Figure 1. "Mugifumi” in Japan;

((A) http://www.monanooka.com/wp/?p=140;

(B) http://www.kurokihonten.co.jp/category/mugi_diary/).

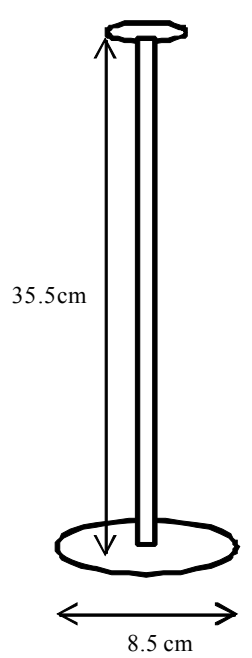

(a)

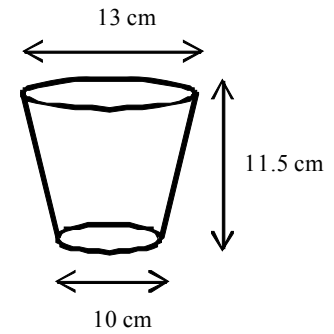

(b)
Figure 2. Treading instrument (a) and growth pot for impact loading (b).

acid in leaves, as well as increasing the contents of aspartic acid and several stress-related free amino acids [4]. Cadmium treatment caused a decrease in flavonoid content by more than $50 \%$ [5].

The alkali stress induced severe reductions in water content, root system activity, and photosynthetic pigment contents, and a sharp increase in the electrolyte leakage rate. These results indicate that a high $\mathrm{pH}$ level from alkaline salts $\left(\mathrm{NaHCO}_{3}\right.$ and $\left.\mathrm{Na}_{2} \mathrm{CO}_{3}\right)$ might damage the root structure and functions such as absorption of water and ions and contents of photosynthetic pigments [6].

Water stress induced a reduction in relative water content, as well as an increase in proline content and endogenous abscisic acid concentrations in all tested genotypes. The lack of water led to a 2-fold increase in proline content for $H$. vulgare var. rihane and a 5-fold increase in endogenous abscisic acid for $H$. vulgare cv. Ardhaoui [7]. While still being subjected to a lack of water, young barley plants were subjected to osmotic stress by treating their roots with $25 \%$ polyethylene glycol. Prior to stress imposition, roots were incubated in nutrient solution containing proline or one of its metabolic precursors, glutamate or ornithine. Foliar proline levels showed a significant increase in ornithine- and proline-pretreated plants compared to the control [8].

Additionally, the spring barley carbohydrate metabolism system takes part in the adaptive response to stress. This is confirmed by an increased accumulation of monosugars in leaves resulting from a high temperature and moisture deficit [9].

UV-B irradiation led to an increase of the amount of UV-B-absorbing compounds, including flavonoids, measured in acidified methanol extract at $300 \mathrm{~nm}$ and of UV-B-induced compounds, with maximum absorbance at $438 \mathrm{~nm}$, extracted in $0.1 \%$ trichloracetic acid. The content of free proline, malondialdehide, and $\mathrm{H}_{2} \mathrm{O}_{2}$ increased as a result of 4 days of treatment with $150 \mathrm{mM}$ $\mathrm{NaCl}, \mathrm{KCl}$, or $\mathrm{NaNO}_{3}$. Salt pretreatment resulted in a considerable decrease in the level of UV-induced and UV-B-absorbing compounds measured $24 \mathrm{~h}$ after UV-B irradiation [10]. While carotenoids are affected very little by $\mathrm{NaCl}$ treatment, UV-B irradiation caused a $5 \%-20 \%$ increased in the carotenoid content of all cultivars [11].

Numerous studies indicate that natural plant flavornoids are important polyphenolic antioxidants, and they are widely used in health food today. In particular, many health food supplements prepared from young green barley are available in world markets. As the various function of young barley has become clearer [12-16] and the use of barley has become more widespread, we focus on the changes in amino acid contents, flavonoid contents, and antioxidant activity in young green barley leaves caused by treading stress.

Treading barley is a unique and important traditional cultivation practice in Japan known as "Mugifumi" in Japanese (Figure 1). The barley treaded lie down on the ground, but rise up in several days, then another treading is applied. This operation is repeated several times. The objective of "Mugifumi" is to induce stress on young green barley to make the stem thicker and the root stronger than usual. This practice is especially effective during cultivation in the rainy season [17]. Although there have been reports about the effects of stress on various plants, to our knowledge no study of the effects of the stress of treading young barley (Mugifumi) has been reported.

\section{Materials and Methods}

\subsection{Plant Material and Growth Conditions}

Two-rowed barley ( $H$. vulgare f. distichon) Nishinohoshi was harvested in 2011. Seeds were sown in planters (41 $\times 20 \mathrm{~cm}$, soil area $820 \mathrm{~cm}^{2}$ ) containing organic fertilizers (SHOEI, Myazaki, Japan) in a growth chamber at $15^{\circ} \mathrm{C}$ $20^{\circ} \mathrm{C}$, at $119.5-140.5 \mu \mathrm{mol} \mathrm{m} \cdot \mathrm{m}^{-2} \cdot \mathrm{s}^{-1}$ (rain or overcast days) or about $1280 \mu \mathrm{mol} \mathrm{m}{ }^{-2} \cdot \mathrm{s}^{-1}$ (clear day) light intensity, and $70 \%$ relative humidity.

Young green barley plants were divided into two 
groups, the control group (without treading) and the treatment group (with treading). The control group was harvested on the 5 th, 10 th, 15 th, and 20 th day after germination. Treading was applied to the treatment group on the 5 th, 10th, and 15 th days after germination, and plants were harvested 5 days after each treading stress (on the 10th, 15th, and 20th day after germination). In both groups of young green barley, the plant height and weight were quantified as growth parameters.

\subsection{Stress Instrument and Treatment}

Treading barley ("Mugifumi") is a process for barley culturing that is unique and indispensable in Japan. Generally, roller machines or human feet are used several times to tread young barley. As a model examination, a stainless steel instrument (250 g) was used for treading barley in this study (Figure 2(a)). The instrument was dropped from a height of $25 \mathrm{~cm}$ onto the surface of planter soil as tread stress, 3 falls per 1 operation, and this 1 operation was applied to young green barley on the 5 th, 10th, and 15th days after germination.

\subsection{Determination of Impact Loading}

To determine the load for treading barley, we used a specific growth pot $\left(13 \mathrm{~cm}\right.$ in diameter, soil area $114 \mathrm{~cm}^{2}$, Figure 2(b)) filled with the same organic fertilizers as we usually use in cultivation. For this experiment, 20 seeds of barley were germinated in the pot. As a control, an identical pot with the same conditions but without sowing was used. The treading instrument $(250 \mathrm{~g}$, surface area $56.7 \mathrm{~cm}^{2}$ ) was dropped from a height of $25 \mathrm{~cm}$. To determine the impact load from the falling instrument, we used a load-cell, which was an elastic octagonal ring with a strain gage attached to it. The load-cell's output was processed through a dynamic strain amplifier to determine the dynamic load. With the output voltage of the dead load $(10.3 \mathrm{~kg})$ as a standard criterion, the dynamic load was estimated based on maximum voltage on the oscillograph profile. The operation was performed 5, 10, and 15 days after germination, 3 falls per day.

\subsection{Determination of Amino Acid Compositions}

Amino acids (except for tryptophan) in the young green barley were determined by automatic amino acid analyzer JLC-500/V (JEOL Ltd., Japan), and tryptophan in the young green barley was measured by an LC-20AD liquid chromatography unit (Shimadzu Corporation, Ltd., Japan). The sample of dry weight was $9.7 \mathrm{~g}$ from control plants $(\mathrm{n}=412)$ and $11.1 \mathrm{~g}$ from treatment plants $(\mathrm{n}=528)$ after treading 2 times.

\subsection{Extraction and Isolation of Compounds}

The freeze-dried powder of young green barley (3.6 g) was extracted with methanol $(180 \mathrm{ml})$ at $60^{\circ} \mathrm{C}$ for $1 \mathrm{~h}$. The water $(10 \mathrm{ml})$ soluble part of this methanol extract was subjected to MCI gel CHP-20P (75 - $150 \mu \mathrm{m}$, Mitsubishi Kasei Co., Japan) column chromatography with 5 $\mathrm{mL}$ of methanol 6 times to afford extracts. Each extract was analyzed by high performance liquid chromatography (HPLC) using a Waters TM 600 Controller, Waters TM 486 Tunable Absorbance Detector, and Waters 600 Multi-solvent Delivery System (Waters Co., Ltd., Japan) at a concentration of $2 \mathrm{mg} / \mathrm{mL}$. Analytical HPLC was conducted on a Wakopack Navi C18-5 column (4.6 i.d. $\times 150 \mathrm{~mm}, 5 \mu \mathrm{m}$, Wako Pure Chemical Industries, Ltd., Japan) using an elution profile as follows: $10 \mathrm{~min}, 100 \%-80 \% \mathrm{~A}$ and $0 \%-20 \% \mathrm{~B} ; 20 \mathrm{~min}, 80 \%$ $70 \% \mathrm{~A}$ and $20 \%-30 \% \mathrm{~B}$; solvent $\mathrm{A}$ was $8.5 \mathrm{mM}$ phosphoric acid/methanol, 8:2, and solvent B was methanol; flow rate was $1.0 \mathrm{~mL} / \mathrm{min}$; injection volume was $10 \mu \mathrm{L}$; detection wavelength was $190 \mathrm{~nm}-500 \mathrm{~nm}$.

The dried powder of young green barley $(245 \mathrm{~g})$ was extracted two times with methanol $(4 \mathrm{~L})$ at $60^{\circ} \mathrm{C}$ for $5 \mathrm{~h}$. Evaporation of the solvent under reduced pressure provided the methanol extract (42 g). The water-soluble part of this methanol extract ( $22 \mathrm{~g}$ ) was subjected to MCI gel CHP20P column chromatography [250 mL; ultrapure water $(500 \mathrm{~mL}) \rightarrow 40 \%$ methanol $(300 \mathrm{~mL}) \rightarrow 60 \%$ methanol $(300 \mathrm{~mL}) \rightarrow 80 \%$ methanol $(300 \mathrm{~mL}) \rightarrow$ methanol $(300 \mathrm{~mL})]$ to give fractions 1 - 10. Fraction 2 (721 mg) was separated by Chromatrex ODS column chromatography [ $20 \%$ methanol $\rightarrow 30 \%$ methanol] to give compound 1 (17 mg). Fraction 3 (594 mg) was separated by Chromatrex ODS column chromatography [40\% methanol $\rightarrow 50 \%$ methanol] to give compound $2(25 \mathrm{mg})$. Fraction 5 (326 mg) was given as crystal and recrystallized by methanol to give compound $3(210 \mathrm{mg})$. Fraction 7 (150 mg) was separated by Chromatrex ODS column chromatography [ $50 \%$ methanol $\rightarrow 70 \%$ methanol] to give compound $4(15 \mathrm{mg})$. Fraction $8(130 \mathrm{mg})$ was separated by Chromatrex ODS column chromatography $[50 \%$ methanol $\rightarrow 70 \%$ methanol] to give compound 5 (35 $\mathrm{mg})$ and compound $6(9 \mathrm{mg})$. The structure of each compound was identified by ${ }^{1} \mathrm{H}$ - and ${ }^{13} \mathrm{C}-\mathrm{NMR}$ spectral data, and the compounds were confirmed to be 3-Oferuloylquinic acid 1) [18], lutonarin 2) [18,19], saponarin 3) $[18,19]$, isovitexin 4) [18], isooreintin-7- $O-[6-$ feruloyl]- $\beta$-glucopyranoside 5) [18], and isooreintin-7- $O$ [6-sinapoyl]- $\beta$-glucopyranoside 6 ) [18]. TLC was performed on pre-coated TLC plates with Silica gel $60 \mathrm{~F}_{254}(0.2$ $\mathrm{mm}$, ordinary phase, Merck KGaA, Darmstadt, Germany), and detection was achieved by spraying with $10 \%$ aqueous $\mathrm{H}_{2} \mathrm{SO}_{4}$ followed by heating. To obtain physical data, we used a ${ }^{1} \mathrm{H}-\mathrm{NMR}$ spectrometer (JEOL, $500 \mathrm{MHz}$ ) and a ${ }^{13} \mathrm{C}-\mathrm{NMR}$ spectrometer (JEOL, $125 \mathrm{MHz}$ ), with tetramethylsilane (TMS) as an internal standard. The experimental conditions mentioned above were used for 
chromatography (30 - $50 \mu \mathrm{m}$, Fuji Silysia Chemical, Ltd., Japan).

\subsection{Determination of Antioxidant Activity}

Antioxidant activity was determined by the method of 1,1-diphenyl-2-picrylhydrazyl (DPPH) radical scavenging assay as described previously by Shimamura et al. [20], with minor modifications. The sample was first dissolved in ethanol or dimethylsulfoxide (DMSO, Wako Pure Chemical Industries, Ltd., Japan). The reaction mixture contained $1000 \mu 1$ of $0.2 \mathrm{mM}$ DPPH (Tokyo Chemical Industry Co., Ltd., Japan) in ethanol, $800 \mu 1$ of $0.1 \mathrm{M}$ Tris-HCl buffer ( $\mathrm{pH} 7.4$ ), and $200 \mu \mathrm{l}$ of sample solution in ethanol or DMSO. After the reaction was carried out at room temperature for 30 minutes, the free radical scavenging activity of the sample was quantified by the decolorization of DPPH at $517 \mathrm{~nm}$.

\subsection{Statistical Analysis}

Data were analyzed using Student's $t$-test. The results are given as means \pm standard deviation, significantly different at ${ }^{* *} \mathrm{p}<0.01$ or ${ }^{*} \mathrm{p}<0.05$.

\section{Results}

\subsection{Model Examination of Impact Load}

We used an impact test to determine the energy absorbed in fracturing of a test piece at high velocity. The main purposes of "Mugifumi" are: 1) to increase the yield, as "Mugifumi" makes the stems and roots thicker, and promotes tillering; 2) to solidify the soil which is loosened with frost in the case of autumn-seeded barley. Generally, roller machines or human feet are used to tread young barley. To date, the impact of treading on barley has not been reported. Therefore, we approached the determination of impact load as a model examination. Table 1 shows result of the impact loads of the treading stresses on young barley performed three times. The table indicates that the loading weight of each impact was approximately $30 \mathrm{~kg}$ on the barley. On each cultivation day, the impact loads were small on the 1 st fall of the machine, because the young green barley adsorbed energy from the loading. The impact loads on the 2 nd fall were greater, and those on the 3rd fall were almost the same as in the case of the control. The results show that with 3 falls, the soil was solidified to the level of the control, and we thus decided the treading time should be three falls per 1 operation as the model of "Mugifumi". The decreased impact loads on the 15th day after germination were due to the growth of barley leaves, which cushion the fall and absorb energy. The pictures of this examination are shown in Figure 3.
Table 1. The impact load by treading instrument for model examination of treading young green barley three times.

\begin{tabular}{cccc}
\hline \multirow{2}{*}{$\begin{array}{c}\text { Culture days after } \\
\text { germ in ation }\end{array}$} & \multicolumn{3}{c}{ Impact load weight (kg) by falling value (v) } \\
\cline { 2 - 4 } & 1st fall & 2nd fall & 3rd fall \\
\hline Control & 37.3 & 37.9 & 37.9 \\
5 & 27.8 & 35.0 & 37.5 \\
10 & 29.4 & 36.4 & 37.4 \\
15 & 21.0 & 33.6 & 34.1 \\
\hline
\end{tabular}
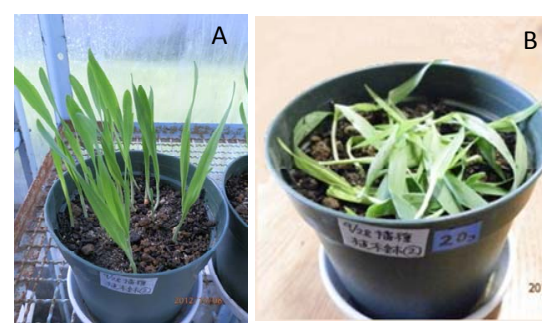

B

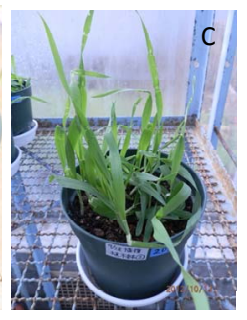

Figure 3. Extermination of impact loading. ((A) Before the treading; (B) Right afer the treading; (C) 5 days afer the treading).

\subsection{Growth Parameters}

The height $(\mathrm{cm})$ and weight $(\mathrm{g})$ of young green barley during our test period are shown in Figures 4 and 5. The height and weight of barley increased significantly from 5 days to 15 days after germination for both the control and treatment groups. However, the results indicate that barley growth was heavily damaged at 5 days after the first treading, when the height was reduced by $37 \%$ compared to the control. However, this ratio went down to $18 \%$ at 10 days after treading twice, and to $17 \%$ at 15 days after treading thrice, as the damage was gradually repaired. In the same way, the reduction in weight was $24 \%$ at 5 days but recovered to $16 \%$ at 10 days and $13 \%$ at 15 days. Treading barley damages plants and decreases growth, such as height and weight of the aerial parts, but the plant improves gradually as the cultivation proceeds.

\subsection{Amino Acid Composition}

Treading as a stress treatment was applied to barley on the 5th and 10th days after germination, and then plants were harvested 5 days later to determine the amino acid compositions. The results are shown in Table 2. The total amino acid contents increased with the treading stress. The treading stress induced a 1.7-fold increase in aspartic acid content and an approximately 1.6-fold increase in glutamic acid, proline, cystine, and methionine contents. The present results indicate that the treading stress influences the amino acid compositions in young green barley. 


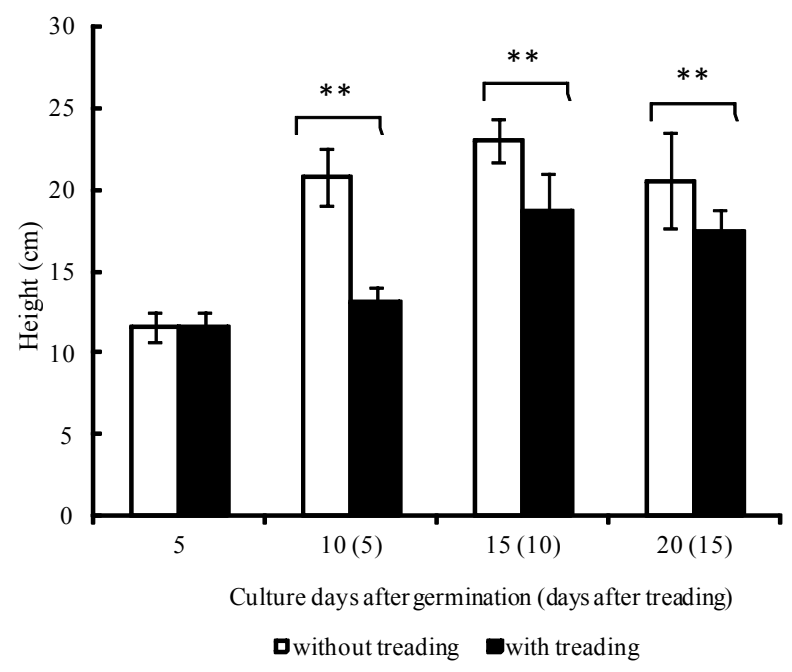

Figure 4. The effect of treading on the growth of young green barley $(n=20$, mean \pm standard deviation, significantly different at ${ }^{* *} \mathrm{p}<0.01$ according to $t$-test).

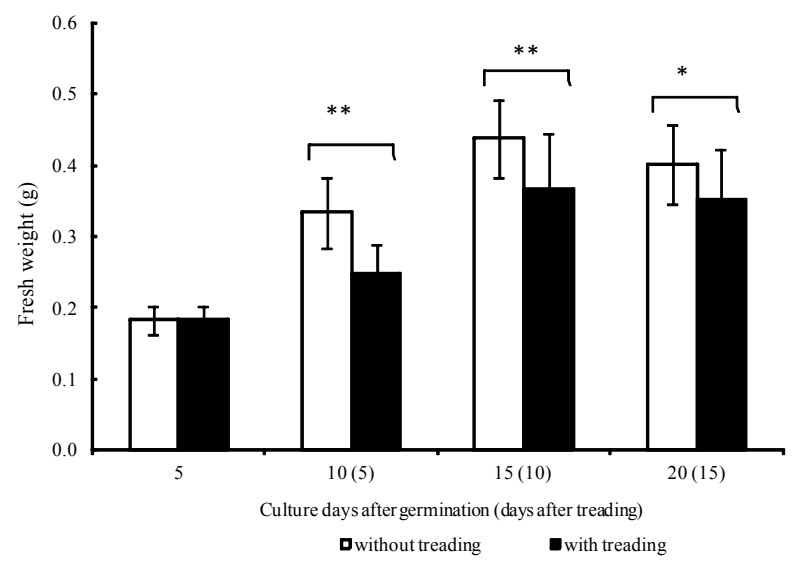

Figure 5. The effect of treading on the growth of young green barley $(n=20$, mean \pm standard deviation, significantly different at ${ }^{*} \mathrm{p}<0.05$ according to $t$-test).

\subsection{Phenolics and Flavonoid Contents}

The results of isolation and purification suggest that the main components of the methanol-soluble fraction from the young green barley are six well-known compounds, including 3-O-feruloylquinic acid 1 ), isoorientin-7-Oglucoside (lutonarin) 2), isovitexin-7-O-glucoside (saponarin) 3), isovitexin 4), isooreintin-7-O-[6-feruloyl]$\beta$-glucopyranoside 5), and isooreintin-7-O-[6-sinapoyl]$\beta$-glucopyranoside 6). Of these, saponarin and lutonarin were the main components. The present results were similar to those presented in previous reports [21]. The quantification of saponarin was achieved based on the absorbance recorded in chromatograms, applying the external standard calibration method and using peak areas. In this quantification, methanol-soluble fraction
Table 2. Amino acid compositions of young green barley.

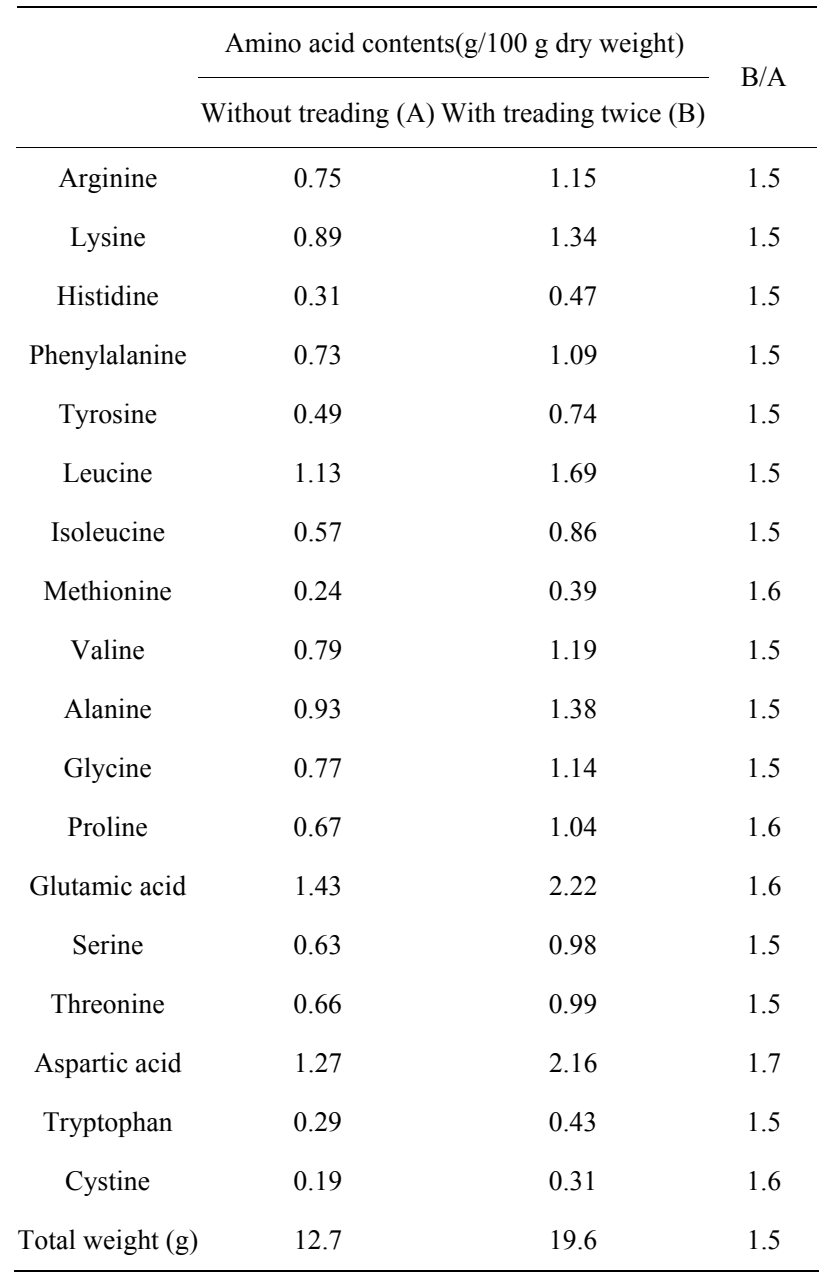

Table 3. Quantification of the saponarin from the methanol extract of young green barley.

\begin{tabular}{ccc}
\hline \multirow{2}{*}{$\begin{array}{c}\text { Culture days after } \\
\text { germination }\end{array}$} & Saponarincontent $\mathrm{mg} / \mathrm{g}$ (vs. methanol extract) \\
\cline { 2 - 3 } & Without treading & With treading \\
\hline 5 & 103 & \\
10 & 166 & 161 \\
15 & 109 & 99 \\
20 & 239 & 172 \\
\hline
\end{tabular}

of young green barley was applied to an MCI gel column and eluted with water and methanol. The methanol eluted fraction was then subjected to HPLC. Table 3 shows the quantification of the saponarin content in the methanolfraction. There was no significant difference between the treatment group and the control group, both of which had a saponarin content of about $160 \mathrm{mg} / \mathrm{g}$ (methanol-soluble fraction). Saponarin and lutonarin are known as potent antioxidants. Two treading treatments significantly in- 


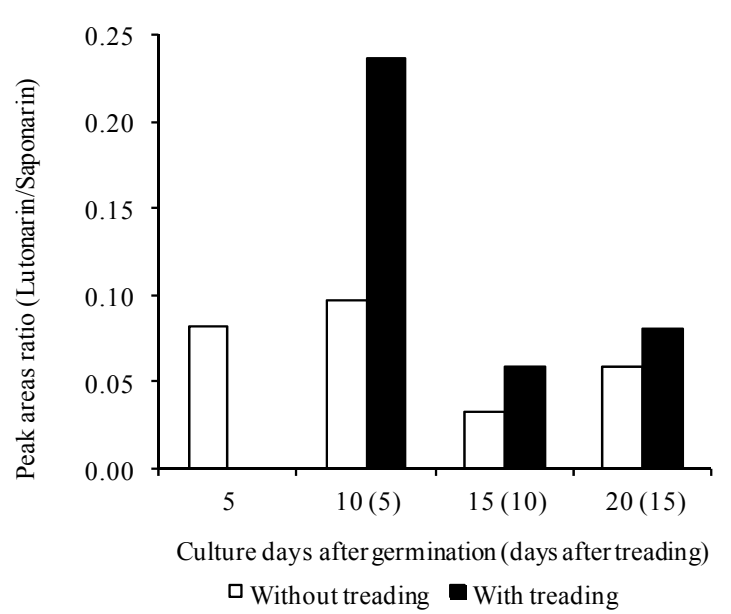

Figure 6. Changes in lutonarin/saponarin peak areas with or without treading.

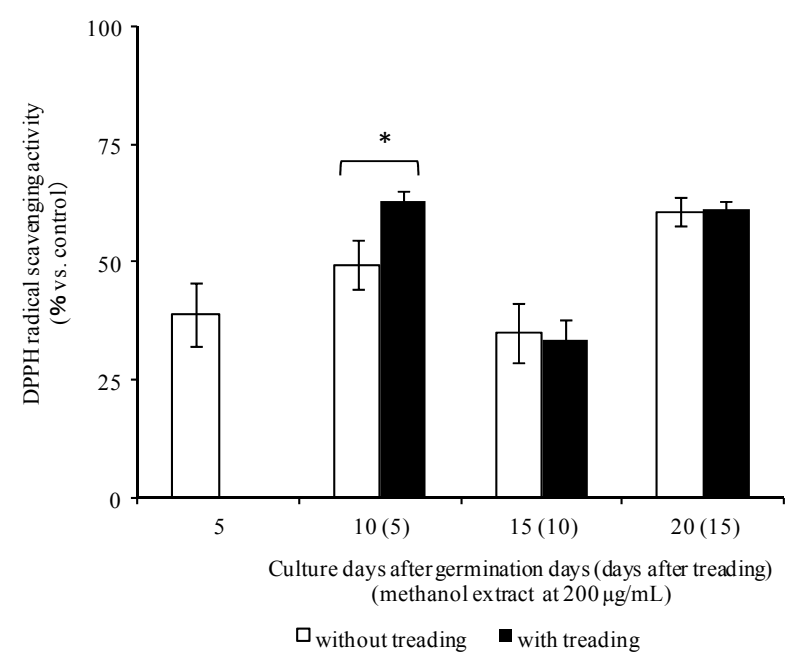

Figure 7. DPPH radical scavenging activities of methanol extract from young green barley (Data are expressed as mean \pm standard deviation of the determinations, $n=3$. $^{*} \mathbf{p}<$ 0.01).

creased the lutonarin/saponarin ratio (Figure 6).

\subsection{Antioxidant Activity}

The antioxidant activity of each methanol-soluble fraction of young green barley was evaluated by the DPPH method. Figure 7 shows the results of DPPH radical scavenging activity ( $\% v v$. control) on each methanolsoluble fraction. Methanol-soluble fractions showed antioxidant activities, particularly at 10 days after germination after one treading treatment, which resulted in $62.8 \%$ activity, while that of the methanol-soluble fraction without treading was $49.5 \%$.

\section{Discussion}

Young green barley is one of the most important func- tional foods in the United States, Europe, and Japan, and the manufacture and sale of young barley has been increasing. We focused on young green barley as a functional food. Our previous studies demonstrated that young green barley possesses certain bioactive components that are beneficial to health, including antihypertensive activity, improvement of red cell deformability, antioxidant activity, and antihypercholesterolemia activeity [13-16]. Since the beneficial effect of barley leaves was determined through the presence of potent antioxidants, barley has received much attention as a useful food supplement for humans to help prevent various diseases.

Our main purpose was to evaluate the effect of treading on the morphology and composition of aerial parts of young green barley. Regarding the morphology, the treading caused obvious stress that affected the height and weight of barley. This temporary suppression works to prevent spindly growth, and to make young green barley more resistant to cold and frost damage and show increased lodging resistance.

Regarding amino acid composition, our results showed that glutamine, asparagine, and leucine were high in barley with or without treading. Although, the amino acid levels are influenced by the condition of cultivation, such as soil, fertilizers, temperature, and so on, these high concentrations of 3 kinds of amino acid in our test were the same as those reported previously [22]. Urquhart and Joy's [23] reported that asparagic acid promotes the metabolism of aged leaves in leguminous plants such as Pisum sativum. In our study, the asparagic acid content was greatly increased, suggesting that asparagic acid is involved in the repair of plants subjected to treading stress. The changes appeared in amino acids in response to treading stress, indicating that different stress factors are important for plant metabolism as they are precursors of both proteins and nucleic acids. Two earlier studies showed only the changes in proline content by the stress of heavy metal [24,25], but other studies showed that water stress induced a remarkable accumulation of free amino acids, such as histidine, valine, isoleucine, leucine, tyrosine, phenylalanine, and especially praline and asparagine [26]. We speculate that the barley treading treatment significantly promoted the synthesis of amino acids, due to the increase in asparagic acid and the increase in the total amount of amino acids produced to promote metabolism to resist the stress.

Six known phenolic compounds were previously isolated and identified from young green barley [18,27-29]. The saponarin content was about $160 \mathrm{mg} / \mathrm{g}$ (methanol-soluble fraction). Recently, several reports have been published about the composition of barley [18,27-29]. Phenolic compounds with antioxidant activity were confirmed, and possible mechanisms for the protective role 
of antioxidants, including flavonoids, phenolic compounds, and other phytochemicals, in plant foods against various stresses were summarized [30].

We evaluated the antioxidant activity of methanolsoluble fractions from young green barley with treading stress. With or without treading, each methanol-soluble fraction showed antioxidant activity. The extract from the 10th day (5 days after the first treading) showed higher antioxidant activity than those of the other extracts. We found that this higher level of antioxidant activity was due to the increase of the lutonarin/saponarin ratio from $10 \%$ to $24 \%$ (Figure 6). Saponarin and lutonarin were previously reported to be antioxidant compounds [21]. We conjecture that the antioxidant components such as lutonarin and saponalin help to scavenge free radicals [31] and to ease the damages caused by treading.

\section{Acknowledgements}

The authors are grateful to Dr. Noboru Fujimoto, Faculty of Agriculture, Kyushu University, for the valuable comments and support regarding the determination of the impact load.

\section{REFERENCES}

[1] S. Yousfi, M. Wissal, H. Mahmoudi, C. Abdelly and M. Gharsalli, "Effect of Salt on Physiological Responses of Barley to Iron Deficiency," Plant Physiology and Biochemistry, Vol. 45, No. 5, 2007, pp. 309-314. doi:10.1016/i.plaphy.2007.03.013

[2] T. Nishimura, "Study on Structure Activity Relationship of a Phytosiderophore, Mugineic Acid," The Pharmaceutical Society Japan, Vol. 126, No. 7, 2006, pp. 473-479.

[3] S. Alam, S. Kamel and S. Kawai, "Amelioration of Manganese Toxicity in Barley with Iron," Journal of Plant Nutrition, Vol. 24, No. 9, 2001, pp. 1421-1433. doi:10.1081/PLN-100106992

[4] A. Vassilev and F. Lindon, "Cd-induced Membrane Damages and Changes in Soluble Protein and Free Amino Acid Contents in Young Barley Plants," Emirates Journal of Food and Agriculture, Vol. 23, No. 2, 2011, pp. 130136.

[5] J. Lachman, J. Dudjak, D. Miholavá, D. Kolihová and V. Pivec, "Effect of Cadmium on Flavonoid Content in Young Barley (Hordeum sativum) Plants," Plant Soil and Environment, Vol. 51, No. 11, 2005, pp. 513-516.

[6] C. W.Yang, H. H. XU, L. L. Wang, J. Liu, D. C Shi and D. L. Wang, "Comparative Effects of Salt-Stress and Alkali-Stress on the Growth, Photosynthesis, Solute Accumulation, and Ion Balance of Barley Plants," Photosynthetica, Vol. 47, No. 1, 2009, pp. 79-86. doi:10.1007/s11099-009-0013-8

[7] A. Thamuer, A. Ferchichi and M. Lopez-Carbonell, "Quantification of Free and Conjugated Abscisic Acid in Five Genotypes of Barley (Hordeum vulgare L.) under Water
Stress Conditions," South African Journal of Botany, Vol. 77, No. 1, 2011, pp. 222-228.

doi:10.1016/j.sajb.2010.08.004

[8] K. V. Kocheva and G. I. Georgiev, "Changes in Foliar Proline Concentration of Osmotically Stressed Barley," Zeitschrift für Naturforschung C. A Journal of Biosciences, Vol. 63, No. 1-2, 2008, pp. 101-104.

[9] G. Šabajeviene, S, Sakalauskiene, S. Lazaauskas, P. Duchovskis, A. Urbonavičiut, G Samuoliene, R. Ulinskaite, J. Sakalauskiene, A. Brazaityte and V. Povilaitis, "The Effect of Ambiet Air Temperature and Substrate Moisture on the Physiological Parameters of Spring Barley," Žemdirbyst Agriculture, Vol. 95, No. 4, 2008, pp. 71-80.

[10] I. Fedina, K. Georgieva, M. Velitchkova and I. Grigorova, "Effect of Pretreatment of Barley Seedlings with Different Salts on the Level of UV-B Induced and UV-B Absorbing Compounds," Environmental and Experimental Botany, Vol. 56, No. 3, 2006, pp. 225-230. doi:10.1016/j.envexpbot.2005.02.006

[11] H. Çakirlar, N. Çiçek, I. Fedina, K. Georgieva, A. Doğru and M. Velitchkova, "NaCl Induced Cross-Acclimation to UV-B Radiation in Four Barley (Hordeum vulgare L.) Cultivars," Acta Physiologiae Plantarum, Vol. 30, No. 4, 2008, pp. 561-567. doi:10.1007/s11738-008-0155-5

[12] Y. Hagiwra, H. Hagiwara and H. Ueyama, "Physiologically Active Substances in Young Green Barley Leaf Extract," Nippon Shokuhin Kagaku Kogaku Kaishi, Vol. 48, No. 10, 2001, pp. 712-725. doi:10.3136/nskkk.48.712

[13] R. Koga, M. Ikeguchi, M. Tsubata, K. Takagaki, N. Irino and R. Kondo, "Hypotensive Effects of $\gamma$-Aminobutyric Acid (GABA) Enriched Young Barley Leaf Powder on Jaoanese Healthy Volunteers," Journal of Japanese Council for Advanced Food, Vol. 15, No. 1, 2012, pp. 28-35.

[14] R. Koga, M. Tsubata, M. Ikeguchi, K. Takagaki, N. Irino and R. Kondo, "Enriched Production of $\gamma$-Aminobutyric Acid on Young Barley Leaves and It Antihypertensive Effect in Spontaneously Hypertensive Rats," The Journal of Japan Mibyou System, Vol. 18, No. 3, 2012, pp. 11-16.

[15] R. Koga, M. Tsubata, M. Ikeguchi, K. Takagaki, N. Irino and R. Kondo, "Young Barley Leaf Powder Adsurbe Bile Acid as One of Mechanisms of Action against Hypercholesterolemia," The Japanese Society for Food Science and Technology, 2012, in Press.

[16] R. Koga, Y. Kido, T. Kamiya, M. Tsubata, M. Ikeguchi, K. Takagaki, N. Irino and R. Kondo, "Study of Component Involved in the Effect of Young Barley Leaf Powder on Defecation," Journal of Japanese Council for Advanced Food, 2012, in Press.

[17] A. Koyanagi and Y. Watanabe, "Mugirui No Saibai to Riyou,” Asakura Publishing Co., Ltd., Tokyo, 2011.

[18] F. Ferreres, P. B. Andrade, P. Valentão and A. GilIzquierdo, "Further Knowledge on Barley (Hordeum vulgare L.) Leaves $O$-Glycosyl- $C$-glycosyl Flavones by Liquid Chromatography-UV Diode-Array Detection Electrospray Ionization Mass Spectrometry," Journal of Chromatography A, Vol. 1182, No. 1, 2008, pp. 56-64. doi:10.1016/j.chroma.2007.12.070

[19] M. Kamiyama and T. Shibamoto, "Flavonoids with Po- 
tent Antioxidant Activity Found in Young Barley Leaves," Journal of Agricultural Food Chemistry, Vol. 60, No. 25, 2012, pp. 6260-6267. doi:10.1021/jf301700j

[20] T. Shimamura, R. Matsuura, T. Tokuda, N. Sugimoto, T. Yamasaki, H. Matsufuji, T. Matsui, K. Matsumoto and H. Ukeda, "Comparison of Conventional Antioxidant Assays for Evaluating Potencies of Natural Antioxidants as Food Additive by Collaborative Study," Nippon Shokuhin Kagaku Kaishi, Vol. 54, No. 11, 2007, pp. 482-487. doi:10.3136/nskkk.54.482

[21] M. Ohkawa, J. Kinjo, Y. Hagiwara, H. Hagiwara, H. Ueyama, K. Nakamura, R. Ishkawa, M. Ono and T. Mohara, "Three New Anti-Oxidative Saponarin Analogs from Young Green Barley Leaves," Chemical Pharmaceutical Bulletin, Vol. 46, No. 12, 1998, pp. 1887-1890. doi: $10.1248 / \mathrm{cpb} .46 .1887$

[22] I. Paulckova, J. Ehrenbergerrova, V. Fiedlerova, D. Gabrovska, P. Havlova, M. Holasova, J. Kopacek, J. Ouhrabkova, J. Pinkrova, J. Rysova and K. Vaculova, "Evaluation of Barley Grass as a Potenial Source of Some Nutritional Substances," Czech Journal Food Science, Vol. 25, No. 2, 2006, pp. 65-72.

[23] A. A. Urquhart and W. K. Joy, "Use of Phloem Exudate Technique in the Study of Amino Acid Transport in Pea Plants," Plant Physiology, Vol. 68, No. 3, 1981, pp. 750754. doi:10.1104/pp.68.3.750

[24] Alia and P. Saradhi, "Prolin Accumulation under Heavy Metal Stress," Journal of Plant Physiology, Vol. 138, No. 5, 1991, pp. 554-558. doi:10.1016/S0176-1617(11)80240-3

[25] R. Kastori, M. Petrovic and N. Petrovic, "Effect of Excess Lead, Cadmium, Copper and Zinc on Water Relations in Sunflower," Journal Plant Nutrition, Vol. 15, No. 11, pp. 2427-2439. doi:10.1080/01904169209364485
[26] Y. Fukutoku and Y. Yamada, "Diurnal Changes in Water Potential and Free Amino Acid Contents of WaterStressed and Non-Stressed Soybean Plants," Japanese Society of Soil Science and Plant Nutrition, Vol. 27, No. 2, 1981, pp. 195-204. doi:10.1080/00380768.1981.10431271

[27] R. Norbaek, K. Brandt and T. Kondo, "Identification of Flavone $C$-Glycosides Including a New Flavonoid Chromophore from Barley Leaves (Hordeum vulgare L.) by Improved NMR Techniqes," Journal of Agricultural and Food Chemistry, Vol. 48, No. 5, 2000, pp. 1703-1707. doi:10.1021/jf9910640

[28] R. Nørbæk, D. Folsted, I. S. Bleeg, B. T. Christensen, K. Brandt and T. Kondo, "Flavone $C$-Glycoside, Phenolic Acid, and Nitrogen Contents in Leaves of Barley Subject to Organic Fertilization Treatments," Journal of Agricultural and Food Chemistry, Vol. 51, No. 3, 2003, pp. 809 813. doi:10.1021/jf0258914

[29] F. Ferreres, Z. Kršková, R. F. Gonçalves, P. Valentão, J. A. Pereira, J. Dušek, J. Martin and P. B. Andrede, "Free Water-Soluble Phenolics Profiling in Barley (Hordeum vulgare L.)," Journal of Agricultural and Food Chemistry, Vol. 57, No. 6, 2009, pp. 2405-2409. doi:10.1021/jf8037727

[30] J. A. Benedet, H. Umeda and T. Shibamoto, "Antioxidant Activity of Flavonoids Isolated from Young Green Barley Leaves toward Biological Lipid Samples," Journal of Agricultural Food Chemistry, Vol. 55, No. 14, 2007, pp. 5499-5504. doi:10.1021/jf070543t

[31] A. D. Sarma, A. R. Mallick and A. K. Ghosh, "Free Radicals and Their Role in Different Clinical Conditions: An Overview," International Journal of Pharma Sciences and Research, Vol. 1, No. 3, 2010, pp. 185-192. 